\title{
Late Onset of Mild Motor Deficits in a Very Low Birth Weight Infant at Preschool Age: A Case Report Presents Specific Difficulties in Visual Motor Skills
}

\author{
Anne-Kathrin Dathe ${ }^{1}$, Iris Mund ${ }^{1}$, Iciar Sanchez-Albisua ${ }^{1}$, Bernd Schweiger ${ }^{2}$, Ursula Felderhoff-Mueser ${ }^{1}$ and \\ Britta Huening ${ }^{1}$
}

${ }^{1}$ Department of Pediatrics I, Neonatology, Pediatric Intensive Care and Pediatric Neurology', University of Duisburg-Essen, Germany

${ }^{2}$ Institute of Diagnostic and Interventional Radiology and Neuroradiology, University of Duisburg-Essen, Germany

Submission: May 09, 2018 ; Published: May 24, 2018

"Corresponding author: Anne-Kathrin Dathe, Department of Pediatrics I, Neonatology, Pediatric Intensive Care and Pediatric Neurology, University Hospital Essen, University Duisburg-Essen, Germany, Email: Anne-Kathrin.Dathe@uk-essen.de

\begin{abstract}
Preterm infants are at risk for motor and cognitive impairments. After-care programs used to identify these deficits are often performed in toddlers only. However, this does not suffice to detect late onset of motor deficits such as in the reported case. The development of a preterm boy is described from birth at a gestational age of 29.6 with $1425 \mathrm{~g}$ into preschool age. Postnatal course was unremarkable, MRI at term equivalent and six years showed mild signs of white matter abnormalities (non-hemorrhagic ventricular dilatation). He developed age-appropriately during his first four years. However, impairments in motor and visual motor skills become obvious with increasing age. Cognitive skills remained nearly constant and no signs of cerebral palsy or ataxia were detected. Visual motor integration constitutes the basis for the acquisition of handwriting skills. Specific and early examinations, especially of fundamental skills needed at school, open a window for therapeutic interventions. The case report demonstrates the necessity of long-term follow-up beyond the first two years.
\end{abstract}

Keywords: preterm infant; very low birth weight; neurodevelopmental outcome; mild motor deficit; visual motor skill; school readiness; fine motor skill; visual perception

Abbreviations: BSID: Bayley Scales of Infant Development; CA: corrected age; DTVP: Developmental Test of Visual Perception; FEW-2: Frostigs Entwicklungstest der visuellen Wahrnehmung 2; M-ABC 2: Movement Assessment Battery for Children; MDI: Mental Developmental Index; MRI: Magnetic Resonance Imaging; PDI: Psychomotor Developmental Index; SD: Standard Deviation; SON-R: Snijder-Oomen Non-verbal Intelligence Test-Revision 2 1/2-7; WPPSI: Wechsler Preschool and Primary Scale of Intelligence.

\section{Introduction}

Preterm infants are at risk of motor and cognitive impairments. The Bayley Scales of Infant Development (BSID II/ III) are widely used for the neurodevelopmental assessment of very low birth weight infants at 2 years of corrected age (CA). However, its predictive value for long-term outcome is rather limited. The Mental Developmental Index (MDI) of BSID II explains $37 \%$ of later cognitive functions and the Psychomotor Developmental Index (PDI) only 12\% of motor functions [1]. Furthermore, the sensitivity of identification of impairment in cognitive function (69.7\% (55.1\%-84.3\%)) and communication (53.2\% (42.0\%-64.5\%)) using BSID III is reduced [2]. The following case indicates a medical necessity of developmental assessments beyond the age of two years.

\section{Case Report}

The patient is a male very preterm infant, who was born at a gestational age of 29.6 weeks due to preterm labor and placenta previa to a Gravida X, Para VIII mother. Birth weight was $1425 \mathrm{~g}$ and APGAR 7/8/9. Surfactant was administered once due to respiratory distress syndrome, Indo-methacin for closure of ductus arteriosus. Post-natal course was unremarkable except for apnea, bradycardia, anemia and grade I retinopathy of prematurity. The patient was discharged with 35.6 weeks post menstruation and weighing 2300g. MRI at term equivalent age and 82 months CA showed asymmetric mild ventricular dilatation, no hemorrhage, no cysts or periventricular leukomalacia (Figure 1). 


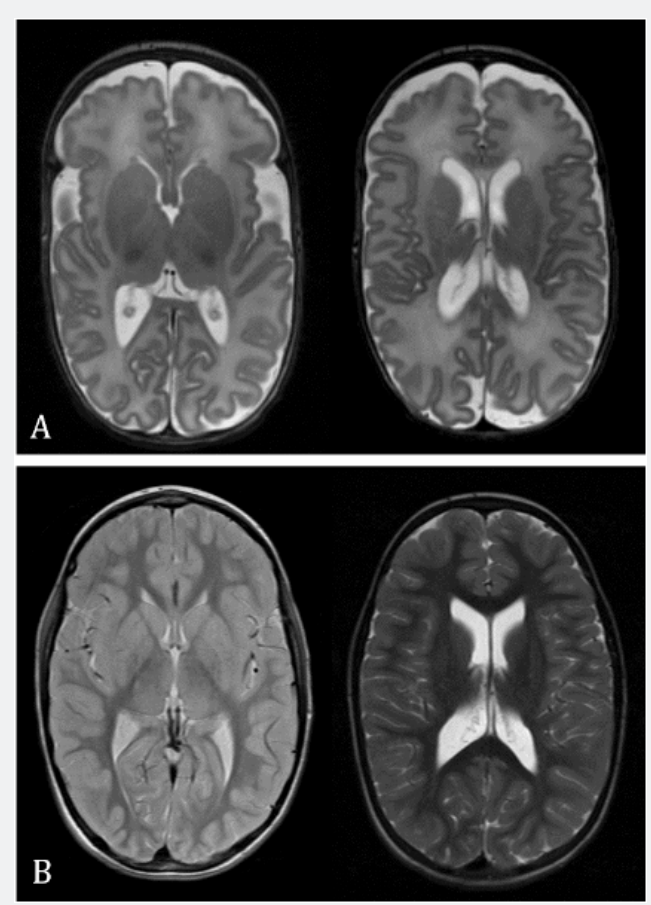

Figure 1: MRI scans (Siemens; Erlangen) $A$ at term equivalent $(1,5 \mathrm{~T})$ and $B$ at 82 months $C A(3 T)$ in axial T2 weighted image showing asymmetric mild ventricular dilatation.

\section{Course of Development}

The patient regularly participated in the neurodevelopmental after-care program of the tertiary university hospital. Until the age of 40 months he developed age-appropriately with regards to cognitive and motor functions without abnormalities in neurological examinations (Figure 2). For the first time he showed impairments in gross and fine motor functions at the CA of 58 months, whereas the general intelligence in the
Wechsler Preschool and Primary Scale of Intelligence (WPPSI IV) improved to 105 (norm 85-115). Neurological tests showed ageappropriate neuromuscular reflexes, no cerebral palsy, no ataxia, but a non-smooth and slow finger opposition, no one-leg jump and unstable one-leg stand. The Movement Assessment Battery for Children (M-ABC 2) revealed movement performance levels in manual dexterity and balance below standard (total standard score 6 , balance 5 , dexterity 5 , ball skills 16 , norm 7-13).

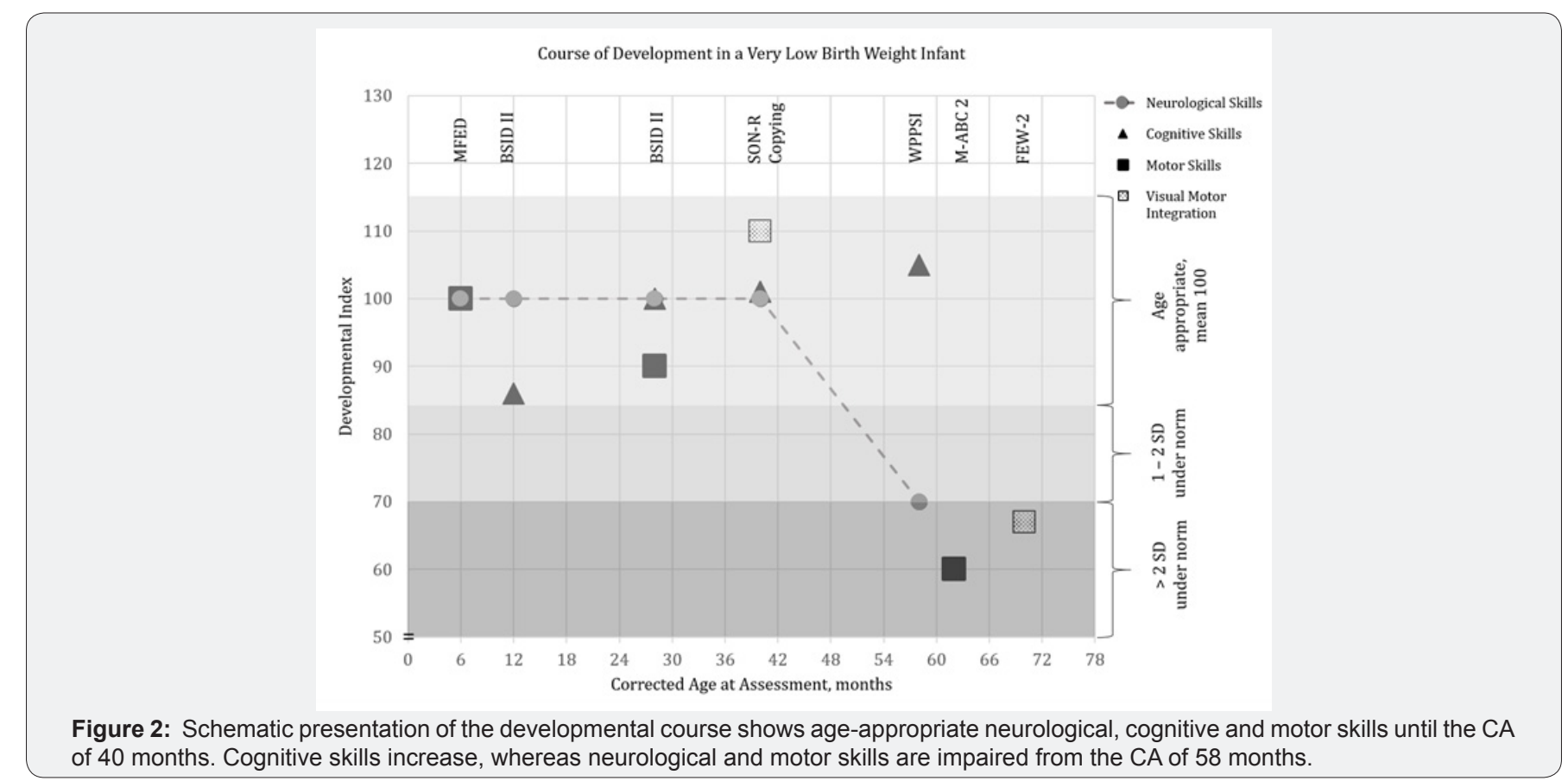


At the CA of 71 months he was tested for fundamental school skills such as visual perception and visual-motor integration using the Developmental Test of Visual Perception (DTVP; German version: FEW-2, Frostigs Entwicklungstest der visuellen Wahrnehmung 2). Visual perception deficits were excluded (Position in Space standard score 8, norm 7-13). However, in Visual-Motor Integration he scored 2 SD under norm (total score 67, norm 85-115). In three of four subtests his visualmotor abilities were below-average and precisely observable (Figure 3). In Visual-Motor Speed he showed decelerated motor sequences and limited precision (standard score 3, norm 7-13).
In the subtest Eye-Hand Coordination change of direction and staying within two lines were difficult (standard score 4, norm 7-13), (Figure 3). In Copying the geometrical figures were skewed, disproportional and imprecise (standard score 4, norm 7-13). The patient was age-appropriate in the Spatial Relation subtest (standard score 9, norm 7-13). In general, he frequently changed the grasp of the pencil from four to five fingers usually with suboptimal angle. However, he had a cramped position of fingers and the whole arm (Figure 3). Consequently, the patient was referred to an occupational therapist to improve his fine and grossmotor skills before school entry.
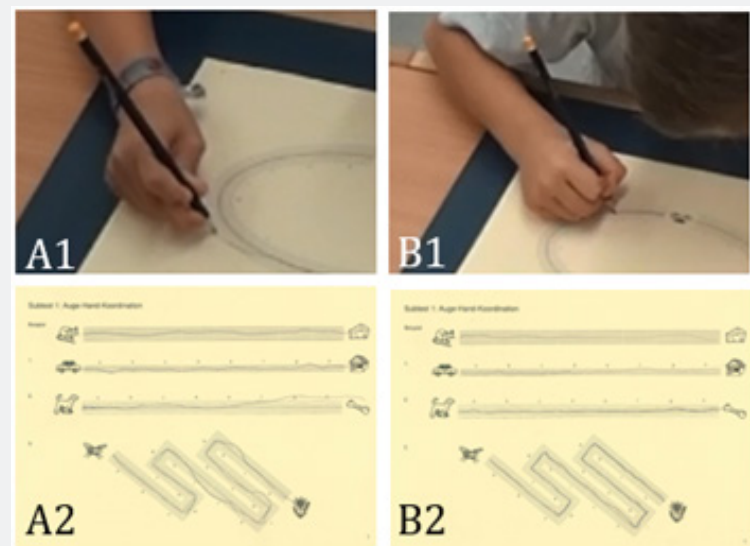
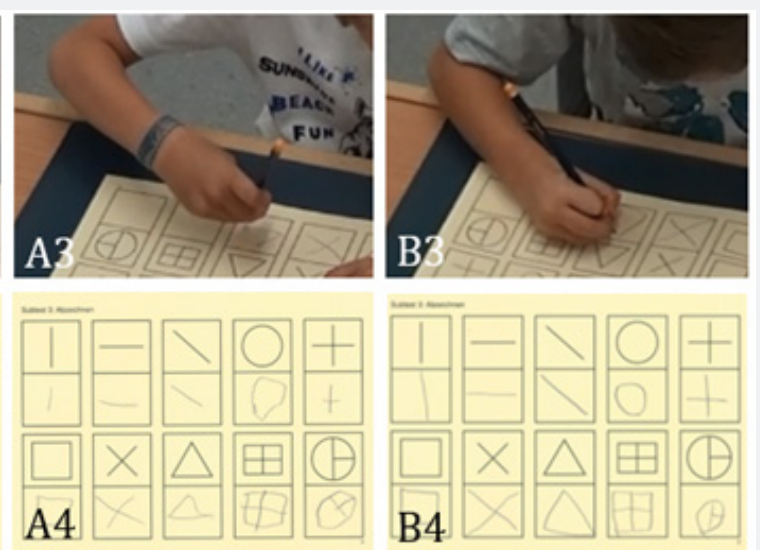

Figure 3: Pencil grasp and visual motor skills of reported preterm boy, 71 months of CA (A) and term born boy, 66 months (B). A1 and A3 shows changing, non-ergonomic, stiff pencil grasp, in contrast to B1 and B3 consistent, flexible, dynamic tripod grasp. A2 presents eyehand-coordination skills under norm, skew broken line, while B2 scored at the 50th percentile, straight unbroken line. A4 shows copying skills under norm, skewed, imprecise, unlike the term born boy. B4 shows copying skills on 50th percentile, exact shapes and curves.

\section{Discussion}

Until the CA of 40 months the patient developed ageappropriately. Mild motor deficits were detected with 58 months CA and visual motor problems with 71 months, respectively. Based on neurologic examinations and scores for BSID II at 28 months CA, these specific problems were unexpected. In fact, the restricted predictive value of the BSID II was reported earlier, especially with regards to motor development [1]. This might be explained by a highly variable and non-linear motor development in children`s early years [3]. Furthermore, the group of preterm infants is heterogeneous comprising a wide-range of known risk factors for development. While some preterm infants grow into deficits after infancy, others may improve [4]. Deficits may only become obvious as the child grows older and demands increase in motor and cognitive skills. This is typically the case during transition into school age.

Visual motor integration such as handwriting is a fundamental skill for children at school [5] and is often a considerable problem for very preterm children, particularly boys [6]. An explanation for these deficits is proposed in basal ganglia damage and cerebellar dysfunction [7]. Visual motor deficits persist from early childhood into adolescence [6] and are consequently related to academic performance [8].
A child who is not able to write accurate letters or within lines, that writes with a cramped and suboptimal pencil posture requires more time than classmates. Furthermore, it pays attention to the process of writing rather than to its content. Suboptimal pencil posture likely consolidates, a spontaneous resolution is rare, while demands to written outputs, frustration and disappointments increase through the years [9]. Thus, early diagnosis of e.g. worse handwriting, pencil grasps or decelerated speed is vital in order to initiate therapy of visual motor skills.

\section{Conclusion and Outlook}

This case report demonstrates the importance of a long-term follow-up in preterm infants. Specific and early examinations, especially of fundamental skills needed at school open a window for therapeutic interventions.

\section{Acknowledgement}

We thank the family for their consent to publish this case.

\section{References}

1. Luttikhuizen dos Santos ES, de Kieviet JF, Königs M, van Elburg RM, Oosterlaan J (2013) Predictive value of the Bayley scales of infant development on development of very preterm/very low birth weight children: A meta-analysis. Early Hum Dev 89(7): 487-496.

2. Wong HS, Cowan FM, Modi N (2017) Validity of neurodevelopmental outcomes of children born very preterm assessed during routine 
clinical follow-up in England. Arch Dis Child Fetal Neonatal Ed, pp. F1F6.

3. Darrah J, Hodge M, Magill-Evans J, Kembhavi G (2003) Stability of serial assessments of motor and communication abilities in typically developing infants-implications for screening. Early Hum Dev 72(2): 97-110.

4. Hack M, Taylor HG, Drotar D, Schluchter M, Cartar L, et al. (2005) Poor predictive validity of the Bayley Scales of Infant Development for cognitive function of extremely low birth weight children at school age. Pediatrics 116(2): 333-341.

5. McHale K, Cermak SA (1992) Fine motor activities in elementary school: preliminary findings and provisional implications for children with fine motor problems. Am J Occup Ther 46(10): 898-903.
6. Geldof CJA, van Wassenaer AG, de Kieviet JF, Kok JH, Oosterlaan J (2012) Visual perception and visual-motor integration in very preterm and/or very low birth weight children: a meta-analysis. Res Dev Disabil 33(2): 726-736

7. Van Braeckel KN, Koenraad NJA, Taylor HG (2013) Visuospatial and visuomotor deficits in preterm children: the involvement of cerebellar dysfunctioning. Dev Med Child Neurol 55 (Suppl 4): 19-22.

8. Taylor Kulp M (1999) Relationship between visual motor integration skill and academic performance in kindergarten through third grade. Optom Vis Sci 76(3): 159-163.

9. Sandler AD, Watson TE, Footo M, Levine MD, Coleman WL, et al. (1992) Neurodevelopmental study of writing disorders in middle childhood. J Dev Behav Pediatr 13(1): 17-23.

\section{Your next submission with Juniper Publishers will reach you the below assets}

- Quality Editorial service

- Swift Peer Review

- Reprints availability

- E-prints Service

- Manuscript Podcast for convenient understanding

- Global attainment for your research

- Manuscript accessibility in different formats

( Pdf, E-pub, Full Text, Audio)

- Unceasing customer service

Track the below URL for one-step submission https://juniperpublishers.com/online-submission.php 